\title{
Estruturas globais de produção e territórios: processos recentes na indústria automotiva em Santa Catarina
}

\author{
Hoyêdo Nunes Lins ${ }^{1}$
}

Resumo: É crescente a presença de cadeias globais na produção e comercialização de produtos industriais. A indústria automotiva é emblemática dessa configuração, e seus movimentos recentes exibem mudanças na organização produtiva e nas interações entre os agentes envolvidos, assim como uma maior presença fora do capitalismo central. O Brasil não ficou à margem, com multiplicação de fábricas (montadoras e fabricantes de autopeças e componentes) que ampliou a capacidade produtiva no país. Ocorreu também reestruturação espacial da indústria, pois novos territórios produtivos foram agregados à associada geografia. Embora tardiamente atingida, Santa Catarina registra movimentos recentes, na sua região nordeste, que intensificam o envolvimento do estado nas correspondentes interações. Algumas repercussões tanto no plano institucional como empresarial fazem-se notar, em processo que introduz um ingrediente a mais no debate sobre o desenvolvimento regional em terras catarinenses.

Palavras chaves: cadeias globais; indústria automotiva; Santa Catarina 


\title{
Global production structures and territories: recent movements in the automobile sector in Santa Catarina
}

\begin{abstract}
Global chains concentrate today a larger and growing share of manufacturing production and trade. Representing a good illustration of such structures, the automotive industry has undergone changes both in production organization and the interactions along its supply lines, besides a greater presence in countries outside the core of capitalism. Brazil has been involved, as the numbers of carmakers and auto parts and components producers increased substantially, enlarging production capacity in the country. Spatial restructuring took place as well, since new places of production were incorporated into the corresponding geography. Santa Catarina was implicated but lately: recent movements in its northeastern region have intensified the state's engagement in the workings of this sector. Some effects have already been observed among institutions and businesses, improving the debate on regional development in Santa Catarina.
\end{abstract}

Keywords: global chains; automotive sector; Santa Catarina

\section{Introdução}

O envolvimento de diferentes territórios e suas atividades em processos cuja determinação situa-se no plano "mundial” sobressai na globalização contemporânea. Esse tipo de participação é histórica, mas atualmente, inclusive por conta dos avanços nos transportes e comunicações, as relações entre as esferas local e global mostram particular intensidade e diversidade de manifestações.

Tem destaque a distribuição das atividades de uma mesma empresa ou um setor entre países ou regiões, assumindo formas representativas de várias lógicas empresariais ou setoriais. Por exemplo: "deslocalização" de capacidades produtivas, com extinção ou atrofia das operações na origem; criação de novas capacidades em outros locais, com aumento do potencial produtivo, sem transferências desde localizações anteriores; subcontratação ou terceirização junto a outras estruturas de produção e comercialização, independentes e instaladas alhures. "Cadeia global" é expressão, com variações na literatura, que orienta o olhar analítico sobre essas configurações. 
Essa expressão da globalização representa o campo de interesse deste artigo, que aborda movimentos recentes na chamada cadeia automotiva global. $\mathrm{O}$ escopo é duplo: de um lado, pretende-se apresentar a problemática das cadeias, em termos gerais, e discutir as mudanças na indústria automotiva à luz do debate sobre as primeiras; de outro, após mostrar que o Brasil foi afetado por tais mudanças, abordar a incidência dessa indústria em Santa Catarina, realçando os processos relativos à instalação de uma fábrica da BMW em Araquari, no nordeste do estado.

O texto baseia-se em consulta a documentos técnicos e institucionais, levantamento de dados em bases estatísticas oficiais e uso de bibliografia principalmente de natureza acadêmica. $\mathrm{O}$ início aborda o tema geral das cadeias globais. Depois a atenção privilegia a cadeia automotiva global. A última parte antes das considerações finais volta-se para Santa Catarina, registrando a presença da produção automotiva e explorando os movimentos vinculados à referida unidade da BMW.

\section{Cadeias globais e desafios associados}

Falar em geografia da acumulação de capital na atualidade significa, em grande medida, referir às estruturas de produção e comercialização chamadas de cadeias globais. É sugestivo que se revele pleno de alusões a tais cadeias o presente debate sobre o desenvolvimento socioeconômico, especialmente quando se realçam as desigualdades, com seus processos subjacentes. Pelo menos desde os anos 1990, ganhou realce na literatura, de fato, a questão das possibilidades de desenvolvimento em ambientes envolvidos com cadeias globais.

São quatro as principais dimensões dessas cadeias, conforme Gereffi (1994; 1995; 1999), e levá-las em conta é útil na abordagem de experiências concretas:

- estruturas de insumo-produto, remetendo ao encadeamento de atividades agregadoras de valor, em produção e serviços;

- territorialidade, relativa à geografia dos vínculos produtivos e comerciais;

- estruturas de governança, correspondendo às relações de poder, incluindo coordenação, controle e determinação produtiva;

- estrutura institucional, representando o domínio dos efeitos, nas operações das cadeias, das iniciativas de política, com reflexos nos âmbitos internacional, nacional e local ou regional. 
Na liderança das cadeias, efetuando o essencial da governança, podem figurar empresas multinacionais fabricantes. As cadeias assim configuradas são "comandadas por produtores", típicas das indústrias automotiva, de computadores ou de aviões, entre outras. Também praticam liderança, controlando os fluxos e realizando as atividades mais "nobres" (design, comercialização final), companhias que, em geral sem produzir diretamente, possuem marcas e têm acesso privilegiado às estruturas de distribuição. Incorporando forças produtivas mundo afora, essas "cadeias comandadas por compradores" tipificam, entre outras, a indústria do vestuário (Gereffi 1999).

A escala nacional não tem exclusividade na abordagem do desenvolvimento em relação com a problemática das cadeias. Assim como a inserção nessas estruturas é desigual entre os países, há contraste, dentro de um mesmo país, entre regiões com maior participação e espaços à margem. Subjazem à situação observada a geografia econômica historicamente plasmada e os interesses e traços das atividades envolvidas e das políticas de desenvolvimento no plano territorial.

Claro que o agravamento das desigualdades inter-regionais, nutrido pela distribuição espacial das atividades produtivas e comerciais enfeixadas em cadeias, interpela as esferas de promoção do desenvolvimento. Iniciativas à altura dos desafios e necessidades costumam ser reivindicadas, no âmbito local ou regional, nos territórios desconectados.

Mas a instigação não é menor nos ambientes enredados pelas cadeias. Galgar posições na divisão espacial do trabalho rumo a funções mais sofisticadas, em percurso de aprendizagem capaz de frutificar em inovações e desempenho competitivo, constitui um legítimo objetivo de política de desenvolvimento local e regional (Gereffi 2001). Em quaisquer latitudes, a regra do jogo atende pelo nome de upgrade ou ascensão industrial.

\section{Cadeia automotiva global: caracterização e envolvimento do Brasil}

A indústria automotiva pode ser descrita como uma cadeia global comandada por grandes produtores, como se falou. Sua configuração apresenta várias camadas de agentes cujas atividades convergem para a montagem de veículos, esfera da qual emanam os principais impulsos ao funcionamento do conjunto. 


\subsection{Aspectos gerais e movimentos recentes no plano mundial}

Na abordagem dessa cadeia, o principal recorte é entre montadoras e fabricantes de autopeças e componentes. As primeiras formam um oligopólio mundial, com grandes empresas de países centrais. O segundo grupo é diversificado e dividido entre fornecedores de equipamentos originais para montadoras e os que miram o mercado de reposição. O centro de gravidade são as montadoras, circundadas por fornecedores em vários níveis, localizados em diferentes países.

Esses aspectos evocam as dimensões "estruturas de insumo-produto" e "territorialidade" das cadeias globais. As dimensões "estruturas de governança" e "estrutura institucional" ganham relevo em considerações sobre as mudanças recentes na produção automotiva mundial.

A década de 1990 registrou situações difíceis para essa indústria nos países ricos e a expansão das respectivas atividades em países em desenvolvimento. Representando o alcance de elevado patamar na internacionalização desse setor, esse período exibiu uma efetiva globalização da produção automotiva, com diferentes estratégias empresariais que espelhavam os processos de aprendizagem e as competências adquiridas pelos fabricantes (Bélis-Bergouignan, Bordenave \& Lung 1996).

Esses movimentos, longe de enfraquecer a governança protagonizada pelas grandes companhias, mantiveram-lhes o peso nas redes de vínculos, mesmo com as mudanças, nas interações entre montadoras e fornecedores, que diminuíram a produção interna das primeiras. Até atividades de projeto foram transferidas para fornecedores líderes, resultando em interações mais densas e intensas, passando tais fornecedores a disponibilizar unidades completas (sistemas, submontagens ou módulos) e a assumir projetos sofisticados, assim como a própria "gestão" de suas relações a montante. Para Sturgeon, Biesebroeck e Gereffi (2008), tais vínculos assumiram uma forma relacional, com dependência mútua escorada em grande especificidade dos recursos dos agentes e em forte confiança (Gereffi, Humphrey \& Sturgeon 2005).

Estrutura modular - ou consórcio modular, segundo Casotti e Goldenstein (2008) - é como se designa essa forma de organizar a produção, em que fornecedores de primeira linha, responsáveis pelos componentes mais complexos, são trazidos para a unidade fabril e participam da própria montagem dos veículos. Com efeito, "[...] desenvolveu-se a espacialização do parque produtivo em condomínios, na qual alguns fornecedores principais trabalham na planta da montadora, em interação constante com esta." (Bahia \& Domingues 2010: 12).

Essas mudanças afetaram o segmento de autopeças e componentes. As novas estratégias das montadoras, provocando fusões e aquisições naquele âmbito, 
resultaram em fornecedores com alcance global, aptos ao global sourcing. Todavia, as montadoras preferem fornecedores que as acompanham (follow sourcing), razão pela qual a difusão geográfica das primeiras gerou uma concomitante difusão dos principais fornecedores.

Assim, desenham-se redes mundiais paralelas, sendo a instalação dos fornecedores nas proximidades das montadoras um aspecto básico da reconfiguração contemporânea da cadeia. Tal movimento diz muito sobre a posição das montadoras nas "estruturas de governança", mas, devido à transferência de funções complexas, fornecedores de primeira linha "[...] estão desafiando as montadoras pelo controle sobre as atividades chaves de alto valor [...]" (Gereffi 1999: 5).

A dimensão "estrutura institucional" manifesta-se de várias formas, como na regulação do comércio externo pelos governos. O mesmo vale para a promoção de empresas locais, capacitando-as à participação no fornecimento: 0 global sourcing e ofollow supply provocaram fortes mudanças patrimoniais, com desnacionalização, em países não centrais (Kaplinski 2000), mas o envolvimento dos maiores fornecedores em atividades complexas permite aos fabricantes locais participarem das outras linhas de fornecimento, para o que se revela importante a promoção no plano institucional.

\subsection{Reflexos no Brasil das mudanças na cadeia automoti-

As mudanças na cadeia automotiva global repercutiram no Brasil. Nos anos 1990, surtos de novos investimentos ampliaram as atividades de fabricantes já instalados e resultaram em novos produtores. Na base figuraram a reestruturação da cadeia em escala mundial e a liberalização do comércio externo do Brasil, entre outras medidas como a criação da Câmara Setorial Automotiva e de um Regime Automotivo, e também o funcionamento do Mercosul. O resultado foi a multiplicação das plantas, com diversificação dos fabricantes. $\mathrm{O}$ faturamento líquido da indústria cresceu bastante, embora o volume de empregos tenha se revelado oscilante (Tabela 1). 
TABELA 1 - INDÚSTRIA AUTOMOTIVA NO BRASIL (AUTOVEÍCULOS E MÁQUINAS AGRÍCOLAS E RODOVIÁRIAS): INVESTIMENTOS, FATURAMENTO E EMPREGO - 1993-2013

\begin{tabular}{cccc}
\hline Ano & $\begin{array}{c}\text { Investimento } \\
\text { (US\$ milhões) }\end{array}$ & $\begin{array}{c}\text { Faturamento líquido } \\
\text { (US\$ milhões) }\end{array}$ & $\begin{array}{c}\text { Empregos } \\
\text { (mil) }\end{array}$ \\
\hline 1993 & 967 & 16.595 & 120,6 \\
1997 & 2.158 & 29.097 & 115,3 \\
2001 & 1.825 & 17.711 & 94,0 \\
2005 & 1.180 & 34.182 & 107,4 \\
2009 & 2.721 & 68.319 & 124,5 \\
2013 & $5.347\left(^{*}\right)$ & 98.881 & 157,0 \\
\hline
\end{tabular}

Fonte: Elaboração do autor com dados da ANFAVEA (2015: 40, 42, 44)

(*) Dado para 2012

A produção saltou de níveis entre 500 mil e dois mil veículos, na década de 1990, para mais de 3,5 milhões no início dos anos 2010. A progressão dos licenciamentos de veículos novos, indicativo das vendas domésticas, foi igualmente notável (Figura 1).

FIGURA 1 - PRODUÇÃO TOTAL E LICENCIAMENTOS DE AUTOVEÍCULOS NOVOS (AUTOMÓVEIS, COMERCIAIS LEVES, CAMINHÕES E ÔNIBUS), MONTADOS E DESMONTADOS - 1990-2014 (UNIDADES)

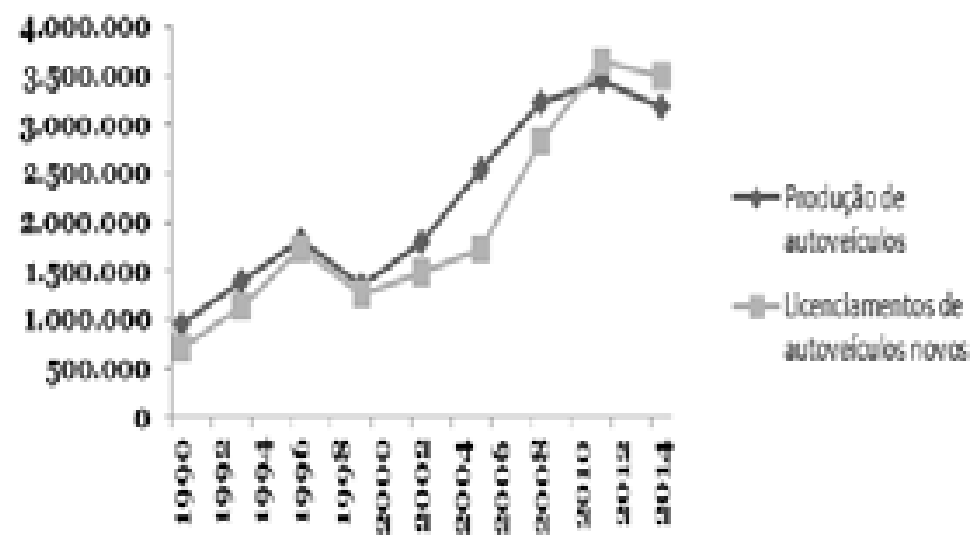

Fonte: Elaboração do autor com dados da ANFAVEA (2015: 57, 61) 
Entre os fabricantes de autopeças já presentes, a maior concorrência provocou reestruturação e um novo perfil produtivo, com inovações organizacionais, programas de qualidade e redução de custos. Tiveram influência as políticas de compras das montadoras, com transferências de funções estratégicas e utilização de global sourcing e following sourcing (Santos \& Costa 1996), com o faturamento, o investimento e o emprego exibindo comportamento cíclico - pico no início dos anos 2010 e posterior contração (Tabela 2). Grandes fornecedores estrangeiros aumentaram sua presença no país, com fusões e aquisições, aprofundando a desnacionalização do segmento.

TABELA 2 - SETOR DE AUTOPEÇAS NO BRASIL: INVESTIMENTOS, FATURAMENTO E EMPREGO - 1996-2014

\begin{tabular}{cccc}
\hline Ano & $\begin{array}{c}\text { Investimento } \\
\text { (US\$ bilhões) }\end{array}$ & $\begin{array}{c}\text { Faturamento líquido } \\
\text { (US\$ bilhões) }\end{array}$ & $\begin{array}{c}\text { Empregos } \\
\text { (mil) }\end{array}$ \\
\hline 1996 & 1,3 & 16,6 & 193 \\
1999 & 1,0 & 11,2 & 167 \\
2002 & 0,3 & 11,3 & 168 \\
2005 & 1,4 & 25,3 & 196 \\
2008 & 0,6 & 41,0 & 207 \\
2011 & 2,4 & 54,1 & 230 \\
2014 & 1.4 & 32,6 & 195 \\
\hline Fonte: Elaboração do autor com dados de SINDIPEÇAS/ABIPECCAS (2015: 8, 9) &
\end{tabular}

Acenando com complementaridades, o Mercosul afetou a trajetória da indústria, influenciando as decisões sobre investimentos e localização de fábricas. Assim, a expansão do comércio externo brasileiro deveu muito ao intercâmbio com a Argentina, embora o México também tenha chegado a sobressair, conforme a tabela 3. Em 2004, a corrente de comércio com a Argentina representou 19\% do total para o Brasil; em 2014, atingiu 29\%.

No conjunto comercializado, a incidência argentina é grande sobretudo em autoveículos: 34\% do total em 2004 e 58\% em 2014. Cresceu a participação de veículos oriundos do país vizinho nas vendas internas brasileiras, indicando que, subjacentes ao comércio, figuraram estratégias das montadoras que incluíam a integração das plantas em unidades de negócios com escala subcontinental (Marinelli 1998), em busca das vantagens da especialização dos produtos e da complementação das atividades. 
TABELA 3 - COMÉRCIO EXTERNO DA INDÚSTRIA AUTOMOTIVA INSTALADA NO BRASIL - 2004 E 2014 (US\$ BILHÕES)

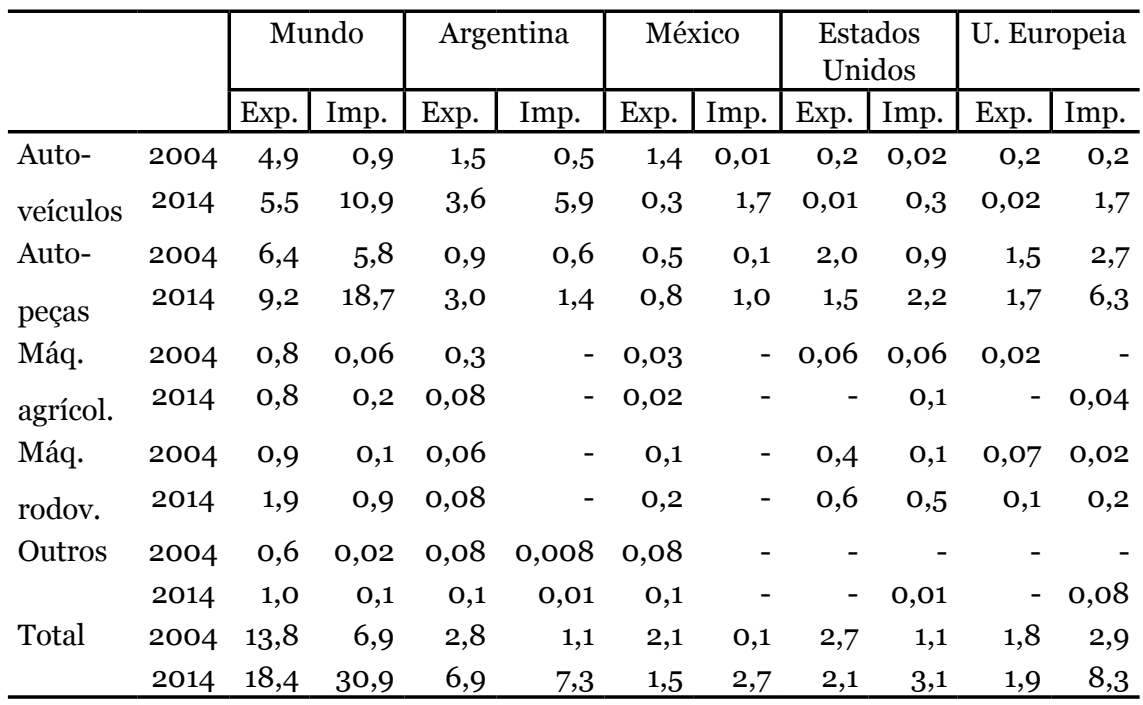

Fonte: Elaborado pelo autor com dados da ANFAVEA $(2015: 48,50)$

Sobre a dimensão "estrutura institucional" das cadeias, deve-se realçar que a trajetória dessa indústria no Brasil é indissociável das iniciativas do Estado. Merecem destaque os acordos de meados dos anos 1990, na Câmara Setorial Automotiva, para aquecer a demanda interna mediante redução dos preços finais praticados e, no médio e longo prazo, ampliar os investimentos, a produção e o emprego.

Ao mesmo tempo, reduziram-se as alíquotas de importação, mas a escalada nas vendas de veículos estrangeiros resultou em ameaças das montadoras sobre transferência para a Argentina. Pressionado, o governo elevou essas tarifas e fixou cotas, além de favorecer as importações de autopeças e insumos e de criar incentivos às exportações, daí resultando um regime automotivo que dava tratamento especial às montadoras em detrimento dos fornecedores.

Em 2012, o governo federal criou o Programa de Incentivo à Inovação Tecnológica e Adensamento da Cadeia Produtiva de Veículos Automotores, conhecido como Inovar-Auto, com vigência até 2017. Escorado em incentivos fiscais, seu foco é triplo: melhorar as condições competitivas dessa indústria, produzir veículos mais seguros e econômicos e promover o desenvolvimento e capacitação da cadeia de fornecimento. A habilitação ao programa exige comprometimento das empresas com metas sobre tais objetivos, devendo-se ressaltar os investimentos em pesquisa e desenvolvimento (P\&D) e os gastos com engenharia e tecnologia industrial básica (Ferreira Filho et al. 2013).

A trajetória narrada incluiu marcada desconcentração espacial das atividades 
de montadoras e fabricantes de autopeças e componentes. Por exemplo, entre 1994 e 1999, o Paraná canalizou 1/3 dos novos investimentos em montadoras, seguido de longe por Minas Gerais, Bahia e Rio Grande do Sul (Santos \& Pinhão 2000). Entre 1996 e 2002, foi inaugurada a metade das unidades que, no final de 2003, compunham aparato capaz de produzir anualmente mais de 3 milhões de veículos e cerca de 86 mil máquinas agrícolas automotrizes, em 48 fábricas distribuídas em 7 estados e 27 municípios (ANFAVEA 2004).

No segmento de autopeças e componentes, o principal movimento foi uma intensa transferência desde a capital de São Paulo para o interior paulista e outros estados. Em 1995, a participação de ambas as esferas, em termos de plantas, era 19\% e 13\%, respectivamente; em 2005, 23,5\% e 28\%. Entre 1995 e 2005, a cidade de São Paulo diminuiu a sua presença na localização de fábricas de 34\% para 18\% do total; o ABCD (Santo André, São Bernardo do Campo, São Caetano do Sul e Diadema), de 18\% para 15\%; o resto da Grande São Paulo, de 17\% para 16\% (SINDIPEÇAS 2006).

Os reflexos no emprego são expressivos. A tabela 4 informa sobre o assunto para 1995, 2005 e 2014. Têm destaque a queda de representatividade da Região Sudeste e a forte expansão da Região Sul. São Paulo foi particularmente afetado, experimentando redução superior a vinte pontos percentuais, e Minas Gerais registrou elevação. Houve ganho principalmente no sul, destacando-se o Paraná: entre 1995 e 2014, o efetivo cresceu quase sete vezes e a participação na totalidade nacional, seis pontos percentuais. Mas também sobressaíram a Região Nordeste, com Pernambuco e Bahia, e, na Região Centro-Oeste, Goiás. 
TABELA 4 - EMPREGOS NA INDÚSTRIA AUTOMOTIVA OPERANDO NO BRASIL - 1995, 2005 E 2014

\begin{tabular}{l|c|c|c|c|c|c}
\hline \multirow{2}{*}{ Referência espacial } & \multicolumn{2}{|c|}{1995} & \multicolumn{2}{c|}{2005} & \multicolumn{2}{c}{2014} \\
\cline { 2 - 7 } & Empregos & $(\%)$ & Empregos & $(\%)$ & Empregos & $(\%)$ \\
\hline Região Norte & 280 & 0,12 & 3.014 & 1,0 & 2.993 & 0,78 \\
Amazonas & 236 & 0,10 & 3.009 & 1,0 & 2.916 & 0,76 \\
Região Nordeste & 916 & 0,39 & 8.099 & 2,7 & 13.108 & 3,4 \\
Pernambuco & 661 & 0,28 & 896 & 0,3 & 3.377 & 0,88 \\
Bahia & 46 & 0,02 & 6.103 & 2,0 & 8.187 & 2,1 \\
Região Sudeste & 220.967 & 93,0 & 238.992 & 79,3 & 294.219 & 76,8 \\
Minas Gerais & 28.197 & 11,9 & 32.270 & 10,7 & 60.293 & 15,7 \\
Rio de Janeiro & 2.723 & 1,15 & 5.850 & 1,9 & 7.937 & 2,1 \\
São Paulo & 189.983 & 80,0 & 200.719 & 66,6 & 225.734 & 58,9 \\
Região Sul & 15.134 & 6,4 & 49.861 & 16,5 & 68.228 & 17,8 \\
Paraná & 4.441 & 1,9 & 25.485 & 8,5 & 30.429 & 7,9 \\
Santa Catarina & 2.667 & 1,1 & 4.798 & 1,6 & 8.295 & 2,1 \\
Rio Grande do Sul & 8.026 & 3,4 & 19.668 & 6,5 & 29.504 & 7,7 \\
Região Centro-Oeste & 197 & 0,08 & 1.269 & 0,42 & 4.517 & 1,2 \\
Goiás & 96 & 0,04 & 1.205 & 0,40 & 4.335 & 1,1 \\
Brasil & 237.494 & 100 & 301.235 & 100 & 383.065 & 100 \\
\hline
\end{tabular}

Fonte: Elaborado pelo autor com dados da RAIS

Obs.: Os dados referem-se às seguintes categorias do Grupo de Atividade Econômica segundo a classificação CNAE/95: Fabricação de automóveis, caminhonetas e utilitários; Fabricação de caminhões e ônibus; Fabricação de peças e acessórios para veículos automotores

\section{Santa Catarina: novos movimentos na indústria auto- motiva}

Santa Catarina registra algumas atividades da indústria automotiva, historicamente. Movimentos recentes ampliam e fortalecem essa presença.

\subsection{Presença de produção automotiva em Santa Catarina}

Santa Catarina nunca figurou com destaque na indústria automotiva. A tabela 4 mostrou que, em 1995, seus correspondentes empregos formais mal superavam $1 \%$ do total nacional. As atividades referem-se à produção de peças e acessórios para veículos ${ }^{1}$ : quase todos os estabelecimentos repertoriados no ano 2000 pelos levantamentos da Relação Anual de Informações Sociais (RAIS) diziam respeito a esse segmento, a expressividade no lado do emprego sendo ainda maior (Tabela 5).

1 Desconsiderou-se a fabricação de cabines, carrocerias e reboques, itens que não representam, propriamente, inputs na produção automotiva. 
As empresas têm portes micro e pequeno, principalmente: naquele ano, os estabelecimentos com até 19 empregados somavam 74\% do total, e o intervalo de 20 a 99 assalariados concentrava 18\%. A imagem é outra quanto ao emprego: não mais de $8 \%$ e de $24 \%$ diziam respeito às unidades de menor escala e de pequeno porte, respectivamente.

TABELA 5 - SANTA CATARINA: ESTABELECIMENTOS E EMPREGOS NA INDÚSTRIA AUTOMOTIVA POR TAMANHO DE ESTABELECIMENTO - 2000, 2007 E 2014

\begin{tabular}{|c|c|c|c|c|c|c|c|c|c|}
\hline & \multicolumn{3}{|c|}{$\begin{array}{c}\text { Fabr. de automóv., } \\
\text { camionetas e } \\
\text { utilitários }\end{array}$} & \multicolumn{3}{|c|}{$\begin{array}{l}\text { Fabricação de } \\
\text { caminhões e } \\
\text { ônibus }\end{array}$} & \multicolumn{3}{|c|}{$\begin{array}{c}\text { Fabr. de peças e } \\
\text { acessórios para } \\
\text { veículos automotores }\end{array}$} \\
\hline & 2000 & 2007 & 2014 & 2000 & 2007 & 2014 & 2000 & 2007 & 2014 \\
\hline \multicolumn{10}{|c|}{ Estabelecimentos } \\
\hline Até 4 & 1 & 1 & $\mathrm{O}$ & $\mathrm{O}$ & 2 & . & 28 & 64 & 64 \\
\hline De 5 a 9 & $\mathrm{O}$ & O & $\mathrm{O}$ & o & $\mathrm{O}$ & $\mathrm{C}$ & 14 & 24 & 26 \\
\hline De 10 a 19 & $\mathrm{O}$ & $\mathrm{O}$ & 1 & $\mathrm{O}$ & $\mathrm{O}$ & $\mathrm{c}$ & 6 & 20 & 33 \\
\hline De 20 a 24 & $\mathrm{O}$ & O & $\mathrm{O}$ & O & 1 & $\mathrm{c}$ & 5 & 9 & 20 \\
\hline De 50 a 99 & $\mathrm{O}$ & $\mathrm{O}$ & $\mathrm{O}$ & O & O & $\mathrm{c}$ & 7 & 13 & 9 \\
\hline De 100 a 249 & $\mathrm{O}$ & o & 1 & O & $\mathrm{O}$ & c & 1 & 5 & 14 \\
\hline De 250 a 499 & $\mathrm{O}$ & $\mathrm{O}$ & $\mathrm{O}$ & O & O & $\mathrm{c}$ & 3 & 3 & 1 \\
\hline De 500 a 999 & $\mathrm{O}$ & $\mathrm{O}$ & 1 & $\mathrm{O}$ & $\mathrm{O}$ & $\mathrm{c}$ & 1 & 1 & 3 \\
\hline $\begin{array}{l}\text { De } 1.000 \text { ou } \\
\text { mais }\end{array}$ & $\mathrm{O}$ & O & o & $\mathrm{O}$ & $\mathrm{O}$ & $\mathrm{c}$ & o & 1 & 1 \\
\hline Total & 1 & 1 & 3 & $\mathrm{O}$ & 3 & & 65 & 140 & 171 \\
\hline \multicolumn{10}{|l|}{ Empregos } \\
\hline Até 4 & 1 & 1 & $\mathrm{O}$ & $\mathrm{O}$ & 2 & & 58 & 127 & 131 \\
\hline De 5 a 9 & $\mathrm{O}$ & $\mathrm{O}$ & $\mathrm{O}$ & $\mathrm{O}$ & $\mathrm{O}$ & $\mathrm{C}$ & 88 & 167 & 169 \\
\hline De 10 a 19 & o & O & 15 & o & O & c & 83 & 306 & 447 \\
\hline De 20 a 24 & $\mathrm{O}$ & $\mathrm{O}$ & O & O & 25 & $\mathrm{c}$ & 138 & 273 & 583 \\
\hline De 50 a 99 & O & O & $\mathrm{O}$ & $\mathrm{O}$ & O & $\mathrm{c}$ & 531 & 949 & 665 \\
\hline De 100 a 249 & O & $\mathrm{O}$ & 222 & O & O & $\mathrm{c}$ & 107 & 827 & 2.038 \\
\hline De 250 a 499 & o & O & o & $\mathrm{O}$ & O & c & 1.071 & 1.170 & 464 \\
\hline De 500 a 999 & $\mathrm{O}$ & O & 519 & o & O & $\mathrm{c}$ & 687 & 991 & 2.003 \\
\hline $\begin{array}{l}\text { De } 1.000 \text { ou } \\
\text { mais }\end{array}$ & O & O & $\mathrm{O}$ & O & O & $\mathrm{c}$ & o & 1.149 & 1.038 \\
\hline Total & 1 & 1 & 756 & 0 & 27 & 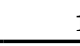 & 2.763 & 5.959 & 7.538 \\
\hline
\end{tabular}

Fonte: elaborado pelo autor com base nos dados da RAIS

Obs.: Os dados referem-se às seguintes categorias do Grupo de Atividade Econômica segundo a classificação CNAE/95: Fabricação de automóveis, caminhonetas e utilitários; Fabricação de caminhões e ônibus; Fabricação de peças e acessórios para veículos automotores 
Esse segmento de peças e acessórios significa diversidade produtiva e oferta para diversos tipos de veículos. Diagnóstico nos anos 1990 identificou um grande conjunto de itens disponibilizados (Bet, Santiago \& Rosa 1997), e, duas décadas depois, a FIESC (2014) divulgou levantamento que reafirma e fortalece esse caráter: numerosas empresas fabricam peças de aço, plástico e elastômeros, além de realizarem usinagem de peças sob encomenda, destacando-se blocos de motores, impulsionadores de partida, escapamentos e peças de suspensão e transmissão. O escoamento dá-se tanto para produtores de autopeças que fornecem para montadoras, quanto diretamente para estas e o mercado de reposição.

Há prática exportadora entre os fabricantes, pois pouco menos de metade vende no exterior, embora com pouca representatividade no faturamento (FIESC 2014). Nos anos 1990, quando essa prática era menor, países vizinhos, especialmente a Argentina, eram os principais mercados. Mas também destinos mais seletivos eram alcançados, notadamente Estados Unidos e Alemanha. Esse perfil se mantém no recente estudo da FIESC (2014), refletindo competitividade nutrida por aperfeiçoamentos observados durante décadas: já nos anos 1990 ocorriam investimentos em equipamentos programáveis até em empresas médias e pequenas, e também inovações organizacionais como esquemas just-in-time, células de manufatura e controle estatístico de processos (Lins 1997).

Essa indústria concentra-se em duas microrregiões: Joinville e Blumenau. Ambas abrigavam 49\% dos estabelecimentos no ano 2000, em proporções próximas (Tabela 6), uma semelhança que não existe nos empregos: enquanto a microrregião de Joinville possuía $17 \%$ do total catarinense, a de Blumenau atingia 37\% (Tabela 7). Adicionando a microrregião de Rio do Sul, tem-se quadro em que pouco menos de $60 \%$ desse emprego encontrava-se no médio e no alto vale do Itajaí em 2000. 
TABELA 6 - SANTA CATARINA: NÚMERO DE ESTABELECIMENTOS DA INDÚSTRIA AUTOMOTIVA POR MICRORREGIÃO - 2000, 2007 E 2014

\begin{tabular}{|c|c|c|c|c|c|c|c|c|c|}
\hline \multirow{2}{*}{$\begin{array}{l}\left.\text { Segmentos( }{ }^{*}\right) \\
\text { Microrregiões }\end{array}$} & \multicolumn{3}{|c|}{$\begin{array}{c}\text { Fabricação de } \\
\text { autom., camionetas } \\
\text { e utilitários }\end{array}$} & \multicolumn{3}{|c|}{$\begin{array}{l}\text { Fabricação de } \\
\text { caminhões e } \\
\text { ônibus }\end{array}$} & \multicolumn{3}{|c|}{$\begin{array}{l}\text { Fabr. de peças e } \\
\text { acess. p/ veículos } \\
\text { automotores }\end{array}$} \\
\hline & 2000 & 2007 & 2014 & 2000 & 2007 & 2014 & 2000 & 2007 & 2014 \\
\hline Araranguá & o & o & 0 & o & o & o & 1 & 8 & 10 \\
\hline Blumenau & o & o & o & o & o & o & 15 & 24 & 28 \\
\hline Campos de Lages & o & o & o & o & 1 & o & 4 & 9 & 12 \\
\hline Canoinhas & o & o & o & o & o & o & 2 & 2 & 3 \\
\hline Chapecó & o & o & o & o & o & o & 3 & 8 & 8 \\
\hline Concórdia & o & o & o & o & o & o & o & 3 & 3 \\
\hline Criciúma & o & o & o & $\mathrm{o}$ & o & o & 6 & 13 & 11 \\
\hline Curitibanos & o & o & o & o & o & o & o & 1 & 0 \\
\hline Florianópolis & o & o & o & o & o & 1 & o & 6 & 11 \\
\hline Itajaí & o & o & o & o & 2 & o & 2 & 10 & 9 \\
\hline Ituporanga & $\mathrm{o}$ & o & o & $\mathrm{O}$ & o & o & o & $\mathrm{O}$ & 1 \\
\hline Joaçaba & o & o & o & o & o & o & 1 & 1 & 5 \\
\hline Joinville & 1 & 1 & 3 & o & o & o & 17 & 22 & 29 \\
\hline Rio do Sul & o & o & o & o & o & o & 4 & 8 & 9 \\
\hline São Bento do Sul & o & o & o & o & o & o & 3 & 3 & 5 \\
\hline S. Miguel do Oeste & o & o & o & o & o & o & o & 6 & 4 \\
\hline Tabuleiro & o & o & o & o & o & o & o & o & o \\
\hline Tijucas & o & o & o & o & o & o & 1 & 2 & 2 \\
\hline Tubarão & o & o & o & o & o & o & 2 & 8 & 12 \\
\hline Xanxerê & o & $\mathrm{O}$ & $\mathrm{O}$ & $\mathrm{O}$ & $\mathrm{O}$ & $\mathrm{O}$ & 4 & 6 & 9 \\
\hline Santa Catarina & 1 & 1 & 3 & 0 & 3 & 1 & 65 & 140 & 171 \\
\hline
\end{tabular}

Fonte: Elaborado pelo autor com base em dados da RAIS

(*) Classificação CNAE/95 Grupo - Fabricação de automóveis, camionetas e utilitários, Fabricação de caminhões e ônibus e Fabricação de peças e acessórios para veículos automotores

Não é só historicamente que Santa Catarina tem pouco destaque na produção automotiva. $\mathrm{O}$ estado ficou à margem, praticamente, dos investimentos registrados pelo Brasil desde meados dos anos 1990. Segundo a tabela 4, a Região Sul concentrava 6\% dos empregos nacionais em 1995, saltou para $16 \%$ em 2005 e atingiu 18\% em 2014. Santa Catarina cresceu de 1,1\% para 1,6\% e depois para $2,1 \%$, embora o efetivo tenha triplicado entre 1995 e 2014. O contraste é forte principalmente com o Paraná, que setuplicou o emprego e passou de menos de $2 \%$ do total nacional para quase $8 \%$. 
TABELA 7 - SANTA CATARINA: VÍNCULOS EMPREGATÍCIOS ATIVOS NA INDÚSTRIA AUTOMOTIVA POR MICRORREGIÃO - 2000, 2007 E 2014

\begin{tabular}{|c|c|c|c|c|c|c|c|c|c|}
\hline \multirow{2}{*}{$\begin{array}{l}\operatorname{Segmentos}\left({ }^{*}\right) \\
\text { Microrregiões }\end{array}$} & \multicolumn{3}{|c|}{$\begin{array}{c}\text { Fabricação de } \\
\text { autom., camionetas } \\
\text { e utilitários }\end{array}$} & \multicolumn{3}{|c|}{$\begin{array}{c}\text { Fabricação de } \\
\text { caminhões e ônibus }\end{array}$} & \multicolumn{3}{|c|}{$\begin{array}{l}\text { Fabr. de peças e } \\
\text { acess. p/ veículos } \\
\text { automotores }\end{array}$} \\
\hline & 2000 & 2007 & 2014 & 2000 & 2007 & 2014 & 2000 & 2007 & 2014 \\
\hline Araranguá & 0 & o & 0 & 0 & 0 & 0 & 20 & 18 & 38 \\
\hline Blumenau & o & o & o & o & o & o & 1.022 & 1.790 & 1.838 \\
\hline Campos de Lages & o & o & 0 & o & 1 & o & 101 & 108 & 144 \\
\hline Canoinhas & o & o & o & o & o & o & 5 & 10 & 15 \\
\hline Chapecó & o & o & o & o & o & o & 8 & 42 & 48 \\
\hline Concórdia & o & o & o & o & o & o & o & 19 & 19 \\
\hline Criciúma & o & o & o & o & o & o & 135 & 242 & 282 \\
\hline Curitibanos & o & o & o & o & o & o & 0 & 1 & 0 \\
\hline Florianópolis & o & o & o & o & o & 1 & o & 109 & 179 \\
\hline Itajaí & o & o & o & o & 26 & o & 10 & 36 & 83 \\
\hline Ituporanga & o & o & o & o & o & o & $\mathrm{O}$ & 0 & 15 \\
\hline Joaçaba & o & o & $\mathrm{o}$ & o & o & o & 2 & 9 & 85 \\
\hline Joinville & 1 & 1 & 756 & o & o & o & 481 & 680 & 1.864 \\
\hline Rio do Sul & o & o & 0 & o & o & o & 595 & 1.387 & 1.375 \\
\hline São Bento do Sul & o & o & o & o & o & o & 14 & 363 & 483 \\
\hline $\begin{array}{l}\text { S. Miguel do } \\
\text { Oeste }\end{array}$ & o & o & o & o & o & o & o & 70 & 181 \\
\hline Tabuleiro & o & o & o & o & o & o & o & o & o \\
\hline Tijucas & o & o & o & o & o & o & 1 & 52 & 30 \\
\hline Tubarão & o & o & o & o & o & o & 6 & 519 & 566 \\
\hline Xanxerê & 0 & 0 & 0 & 0 & 0 & 0 & 382 & 504 & 293 \\
\hline Santa Catarina & 1 & 1 & 756 & 0 & 27 & 1 & 2.763 & 5.959 & 7.538 \\
\hline
\end{tabular}

Fonte: Elaborado pelo autor com base em dados da RAIS

(*) Classificação CNAE/95 Grupo - Fabricação de automóveis, camionetas e utilitários, Fabricação de caminhões e ônibus e Fabricação de peças e acessórios para veículos automotores

Todavia, Santa Catarina não deixou de registrar movimentos importantes mais recentemente. Um refere-se à instalação em Joinvile, com início de funcionamento em fevereiro de 2013, de fábrica da General Motors (GM) que produz motores e cabeçotes para as unidades dessa empresa em Gravataí (RS) e Rosario (Argentina). Outro diz respeito à fábrica da BMW erigida em Araquari, município vizinho a Joinville, assunto abordado em seguida. Registre-se que a Sinotruck, fabricante chinês de caminhões, logrou habilitação e homologação do governo brasileiro, quanto à participação no já referido Inovar-Auto, para instalar no município de Lages o que deverá ser a sua primeira unidade fora da China (Gomes 2014). 


\subsection{Novos movimentos e o aparente surgimento de um "eixo" Araquari-Munique}

A microrregião de Joinville apresentou salto no emprego da indústria automotiva entre 2007 e 2014. Nos estabelecimentos, esse espaço continua a dividir a primazia estadual com a microrregião de Blumenau, somando juntos $33 \%$ do conjunto em 2014 (Tabela 6). Mas, nos empregos, aquela área passou a ostentar 756 registros em "Fabricação de automóveis, camionetas e utilitários", e os números para "Fabricação de peças e acessórios para veículos automotores" quase triplicaram de 2007 a 2014 (Tabela 7). A fábrica de motores e cabeçotes da GM e a montadora da BMW respondem pelo essencial do processo que fez essa microrregião totalizar em 2014, nos três segmentos da produção automotiva considerados, $31 \%$ do agregado catarinense.

A instalação da montadora, especificamente, representa um marco especial no estado, em razão das exigências da atividade e de sua potencial capacidade de mobilização, envolvendo comando e coordenação. O seu anúncio não foi visto como portador de poucas promessas, especialmente no nordeste do estado.

Não tardou para que, subvertendo um cotidiano típico de pequenas localidades, Araquari passasse a viver uma grande expectativa. O município, com menos de 30 mil habitantes, deixou de ser apenas uma cogitação quando a BMW e o governo estadual assinaram, em meados de 2013, o protocolo de intenções sobre a instalação do que seria a primeira montadora de automóveis dessa empresa na América do Sul.

Parecem ter influenciado a localização a proximidade de vários portos (Itapoá, Navegantes, São Francisco do Sul, Itajaí e, no estado vizinho ao norte, Paranaguá), a estrutura rodoviária existente (BR 101), aeroportos (Joinville, Navegantes) e a forte tradição eletrometalmecânica da região, onde se localiza Joinville, maior cidade e principal polo da indústria dinâmica catarinense. Essa tradição representa importantes externalidades, refletindo-se em possibilidades de fornecimento e serviços de apoio. Em dezembro de 2013, deu-se o lançamento da pedra fundamental de uma planta definida para produzir cinco modelos de carros nos segmentos luxo e premium.

A instalação dessa fábrica inscreve-se em percurso de internacionalização da BMW com incidência em vários países, em estratégias que priorizam o abastecimento de mercados regionais. No Brasil, o Grupo BMW intensificara a sua presença desde meados dos anos 1990, com atividades em serviços e produção (montagem de motocicletas em Manaus). A unidade foi oficialmente inaugurada em 9 de outubro de 2014, e o primeiro modelo a sair da linha de montagem foi o BMW 3 Series, um sedã com vendas expressivas internacionalmente e no Brasil.

Mudanças importantes passaram a ocorrer em Araquari desde o final de 2013. Movimentos de terra e obras logo começaram a marcar a paisagem às margens 
da BR-101, e a atração impulsionada pelas primeiras alusões a Araquari como localidade prestes a abrigar atividades de produção de automóveis nutriu dinamismo representativo de aumento populacional. O mercado imobiliário, com sinais de aquecimento e elevação nos preços, foi um eloquente reflexo das reverberações locais (Voos \& Silva 2014).

Mas as repercussões no estado eram amplas mesmo antes da inauguração, pois na contígua Joinville registrara-se intensificação do processo de capacitação profissional com vistas ao aproveitamento da mão de obra local. Em Florianópolis, a FIESC ampliara o destaque atribuído a esse setor na sua agenda de atividades, como sugerido pelo conjunto de relatórios sobre o funcionamento da Câmara de Desenvolvimento da Indústria Automotiva criada naquela instituição, disponível em http://www.fiesc.com.br/camaras-especializadas/setoriais.

O processo de capacitação profissional parece ter ganhado em intensidade no nordeste do estado ao longo do tempo. Segundo Froehlich (2015), a BMW passou a treinar empregados com numerosos instrutores alemães, muitos para atuação como supervisores, destinados a liderar grupos no processo de fabricação. O treinamento ocorria em réplica da linha de montagem instalada em Joinville, com milhares de peças desembarcadas nos portos de Navegantes e Itapoá.

As atividades de fabricação de autopeças e componentes instaladas historicamente em Santa Catarina não se mostraram refratárias aos acenos de dinamização produtiva. Diversas empresas logo passaram a considerar a anunciada presença da BMW nas suas estratégias. Por exemplo, relatório da Câmara de Desenvolvimento da Indústria Automotiva da FIESC, referente a dezembro de 2012, informa a realização, naquele ano, de duas reuniões extraordinárias para que fabricantes instalados no estado apresentassem os seus produtos. Participaram ArcelorMittal Vega, Caribor, Ciser, Hengst, Jofund, Metisa, NOS, Plasticoville, Remy, Reserplastic, Rudolph, Saraiva, Schulz, Tuper, Tupy, Wiest, Zen e ZM (FIESC, 2012).

Esse enredo ilustra o sentido da ocorrência, num dado território, de iniciativa apta a movimentar a economia com induções e efeitos multiplicadores. Mais ainda, chama a atenção para os reflexos locais de grandes investimentos realizados sob o signo da globalização. A BMW amplia substancialmente o vínculo do nordeste catarinense com a cadeia automotiva global, uma relação já intensificada com a mencionada fábrica da GM em Joinville, produtora de motores e cabeçotes. Mas agora é de montagem de automóveis que se trata, significando que confluirão para a região peças e componentes de diferentes origens.

O grau de envolvimento de empresas catarinenses, com mais razão do nordeste do estado, na rede de suprimento da planta em Araquari definirá grande parte das possibilidades locais associadas ao empreendimento da 
BMW. Falar em efeitos de indução, de encadeamento e em multiplicadores, com adensamento das interações na escala territorial, significa aludir, antes de tudo, a essa participação.

No início das atividades da montadora, em outubro de 2014, ocorria na fábrica somente a montagem dos veículos, mas previa-se que logo passassem a ser realizadas a soldagem e a pintura. Avanços nesse sentido parecem ter sido logrados, pelo menos em relação à segunda. A empresa Atriumetal, de Araquari, forneceu (por meio da alemã Durr, que abastece a BMW de forma direta) um dos tanques de aço carbono dentro dos quais os carros da BMW ficam submersos na primeira fase da pintura (Nunes 2014).

De todo modo, cabe indagar, refletindo sobre as possibilidades locais ou regionais e considerando os fluxos de valor agregado, sobre o quanto da estrutura de que participa a planta de Araquari tem (terá) uma "ancoragem" de fato regional ou mesmo estadual.

A BMW beneficiou-se dos incentivos fiscais do Programa Inovar-Auto, que exige a realização no Brasil, pelos fabricantes de veículos, de um número mínimo de atividades fabris e de infraestrutura de engenharia (segundo o Decreto n. 7.819/12, de 3 de outubro de 2012, que regulamenta os art. 40 a 44 da Lei n. 12.715, de 17 de setembro de 2012 - cf. Brasil 2012), assim como gastos locais em $\mathrm{P} \& \mathrm{D}$ numa proporção definida em relação à receita bruta total de vendas.

No começo da montagem em Araquari, as peças fabricadas no Brasil representavam cerca de $25 \%$ do total utilizado, com previsão de atingir 30\% em breve, conforme Loetz e Benetti (2014). O presidente da BMW no Brasil informou na inauguração que fornecedores locais já estavam sendo mobilizados, como no suprimento de bancos. Mas disse que o corte das chapas de aço e a fabricação dos motores continuariam a acontecer na Alemanha (Ettore 2014).

Assim, é pertinente perguntar sobre o perfil das relações de fornecimento que implicarão empresas atuando no Brasil e, sobretudo, em Santa Catarina. Materializados em práticas concretas, os vínculos deverão refletir a política do Grupo BMW como um todo, definindo as chances locais. Ajuda a pensar sobre isso o teor de encontros com representantes da montadora efetuados no seio da aludida Câmara de Desenvolvimento da Indústria Automotiva, da FIESC. Reunião em 2013, com o Diretor de Operações responsável pela gestão da planta de Araquari, mereceu o seguinte registro:

Detalhamento da Planta Fabril:

$[\ldots]$

- A proposta não é importar grandes conjuntos, mas sim fazer toda a 
montagem na planta. O intuito é que a fábrica administre cerca de 11 mil itens.

$[\ldots]$

- O processo de compra ainda é realizado totalmente pela Alemanha, não existe equipe de compras no Brasil. Os setores iniciais [envolvendo compras locais] serão: Power train, peças plásticas pintadas, tanques de combustível e bancos. (FIESC 2013: p. 2).

Indagar sobre esse assunto justifica-se plenamente, pois informações disponíveis no site do Grupo BMW indicam que suas compras distribuíam-se do seguinte modo em 2014: Alemanha, 47,2\%; Europa do Leste, 17,2\%; resto da Europa Ocidental, 15,9\%; NAFTA, 14,5\%; Ásia/Austrália, 3,7\%; África, 1,5\% ${ }^{2}$.

De toda maneira, as estratégias de operação e organização da BMW diferem conforme a "espessura" e a capacitação dos tecidos empresariais e institucionais, nos ambientes em que se instala. Comparando o modus operandi no leste da Bavária - para onde a empresa, sediada em Munique, avançou no final dos anos 1960 - e na província de Rayong, na Tailândia, escolhida no final dos 1990 como pilar de sua investida no sudeste asiático - , Coe et al. (2004: 480) sublinham situação de

[...] forte conectividade intrarregional entre atores para a região da Bavária do leste, tanto em termos de fluxos materiais como de cooperação tecnológica/organizacional, com amparo em instituições regionais. Entretanto, os principais condutores do desenvolvimento são extra locais, baseados na estratégia de produção e no investimento da BMW, ao passo que as decisões prévias de política e os subsequentes fluxos de capital dos governos bávaro e federal ajudaram a deflagrar o desenvolvimento regional. A rede de produção ligada à BMW na área Rayong/Samutprakarn, por outro lado, mostra, geralmente, poucos vínculos regionais em termos comparativos. A maioria das peças e componentes é importada da Alemanha [...] e o investimento, assim como a transferência de tecnologia para fornecedores tailandeses, tem sido, até agora, antes [rather] modesto.

Como assinalado, no tipo de cadeia global que caracteriza a indústria automotiva, o comando e o controle são amplamente exercidos pelas montadoras, que mobilizam em numerosos países e regiões as capacidades empresariais

2 Cf. http://www.bmwgroup.com/e/0_0_www_bmwgroup_com/verantwortung/lieferkette/ueberblick.html Acesso em: 19 de dezembro de 2015 . 
para os vários níveis de fornecimento. Esse engajamento, que gera redes de vínculos com diferentes camadas, é balizado por exigências em tecnologia, organização produtiva e qualidade.

Assim, nos espaços de localização das montadoras, não se pode prescindir de políticas de promoção industrial para apoiar e estimular o envolvimento das empresas nessas interações. Na sua formulação e execução é essencial o engajamento do setor público, do tecido institucional e da base industrial interessada.

\section{Considerações finais}

O Brasil e (mesmo "tardiamente") Santa Catarina não ficaram ao largo das mudanças experimentadas nas últimas décadas pela cadeia automotiva global. Surtos de investimentos vincaram o território do país, num processo que parece longe de arrefecer, embora a atual conjuntura brasileira (2015 e o cenário para 2016) mostre-se pouco estimulante para novos investimentos.

De todo modo, a BMW anunciava vagas em diferentes atividades no primeiro semestre de 2015: operações na montagem, pintura, carroceria e atuação em empilhadeiras, assim como atribuições em compras e logística, compunham o leque de interesses. Tal informação é auspiciosa, mesmo que a degradação do quadro econômico não permita supor que essa vitalidade se manterá.

Entretanto, deve-se pensar em termos mais estruturais sobre o que está em curso em Santa Catarina e no nordeste do estado. Romper barreiras porventura existentes para uma adequada participação das empresas locais nos vínculos de fornecimento de peças e componentes é requisito para efeitos de indução e encadeamento.

De fato, em arranjos produtivos como o esboçado naquela região, essas relações podem ser de suprimento direto às montadoras ou de vendas para fornecedores destas. Em quaisquer circunstâncias, políticas de promoção e ações condizentes mostram-se essenciais para que um fértil envolvimento da base produtiva local possa ocorrer. O objetivo a perseguir deve ser ambicioso, mirando a presença em fornecimento de, mais do que só autopeças, sistemas completos, em vínculos de natureza relacional.

Não se deveria cogitar algo diferente sobre o que se desenha no nordeste catarinense. Medidas de apoio e fomento, formuladas e aplicadas em meio a 
articulações entre o setor público, a base industrial e o tecido institucional, poderão propiciar resultados promissores na face atlântica do "eixo" Araquari-Munique em constituição. Diz-se "eixo" porque, sendo a planta de Araquari a única da BMW a produzir automóveis na América do Sul, a "presença" da sede - ou, dito com estilização, de Munique - deverá se mostrar intensa no nordeste catarinense.

Possibilidades para a área certamente surgirão e florescerão. Explorá-las estrategicamente há de ser um objetivo importante no estado.

\section{Referências bibliográficas}

ANFAVEA (2004). Anuário da indústria automobilística brasileira. São Paulo.

ANFAVEA (2015). Anuário da indústria automobilística brasileira. São Paulo.

Bahia, L. D. \& Domingues, E. P. (2010). "Estrutura de inovações na indústria automobilística brasileira.” Texto para Discussão 1472, IPEA.

Bélis-Bergouignan, M.-C. \& Bordenave, G. \& Lung, Y. (1996). "Global strategies in the automobile industry." Actes du GERPISA 18.

Bet, E. \& Santiago, M. S. De \& Rosa, M. (1997). A indústria automobilística e o segmento de autopeças em Santa Catarina. Florianópolis: BRDE/FIESC.

Brasil (2012). Decreto n. 7.819/12, 3 de outubro. URL [On line]: http://www.planalto.gov.br/ccivil_03/_ato2011-2014/2012/Decreto/D7819.htm Acesso em: 19 de dezembro de 2015.

Casotti, B. P. \& Goldenstein, M. (2008). "Panorama do setor automotivo: as mudanças estruturais da indústria e as perspectivas para o Brasil.” BNDES Setorial 28: 147-188.

Coe, N. M. \& Hess, M. \& Yeung, H.w-C. \& Dicken, P. \& Henderson, J. (2004). “Globalizing' regional development: a global production networks perspective." Transactions of the Institute of British Geographers 29: 468-484.

Ettore, J. (2014). "BMW inaugura sua $1^{\text {a }}$ fábrica no Brasil, em Araquari, SC.” G1 Santa Catarina, 9 out. URL [On line]: http://g1.globo.com/sc/santa-catarina/ noticia/2014/10/bmw-inaugura-sua-1-fabrica-no-brasil-em-araquari-sc.html Acesso em: 19 de dezembro de 2015.

Ferreira Filho, V. S. \& Pascoal, E. T. \& Silva, A. C. \& Olivares, G. L. \& Rocha, H. M. (2013). "Inovar-Auto \& alianças estratégicas: um novo cenário de cooperação para montadoras e fornecedores de auto-peças.” X Simpósio de Excelência em Gestão e Tecnologia, Resende. URL [On line]: http://www.aedb.br/seget/ arquivos/artigos13/5371866o.pdf. Acesso em: 13 de dezembro de 2015.

FIESC (2012). Relatório das atividades das câmaras especializadas da FIESC: 
Câmara de Desenvolvimento da Indústria Automotiva. Florianópolis: FIESC, dez. URL [On line]: http://fiesc.com.br/sites/default/files/medias/relatorio_automotiva_dezembro_2012.pdf?_ga=1.155591679.556475145.14293974 31 Acesso em: 19 de abril de 2015.

FIESC (2013). Relatório das atividades das câmaras especializadas da FIESC: Câmara de Desenvolvimento da Indústria Automotiva. Florianópolis: FIESC, fev. URL [On line]: http://fiesc.com.br/sites/default/files/medias/2013_-_fevereiro_o.pdf Acesso em: 16 de dezembro de 2015.

FIESC (2014). A indústria automotiva em Santa Catarina. Florianópolis: FIESC.

Froehlich, A. (2015). “Fase de treinamento para equipe da BMW no Estado.” Diário Catarinense 17 maio:16.

Gereffi, G. (1994). "The organization of buyer-driven global commodity chains: how U.S. retailers shape overseas production networks.” In GEREFFI, G. \& KORZENIEWICZ, M. (eds.). Commodity chains and global capitalism. London: Greenwood Press, pp. 95-122.

Gereffi, G. (1995). "Global production systems and third world development.” In STALLINGS, B. (ed.). Global change, regional response: the new international context of development. Cambridge: Cambridge University Press, pp. 100-142.

Gereffi, G. (1999). A commodity chains framework for analyzing global industries. Durham: Duke University, Aug. URL [On line]: http://www.azc.uam.mx/socialesyhumanidades/o6/departamentos/relaciones/Pdf.\%20De\%20curso\%20 de\%20MESO/Gereffi\%201999.pdf Acesso em: 10 de julho de 2014.

Gereffi, G. (2001). "Las cadenas productivas como marco analítico para la globalización.” Problemas del Desarrollo 32(125): 9-37.

Gereffi, G. \& Humphrey, J. \& Sturgeon, T. (2005). “The governance of global value chains.” Review of International Political Economy 12(1): 78-104.

Gomes, P. (2014). “Governo autoriza instalação de fábrica chinesa em Lages.” Zero Hora, 30 jul. URL [On line]: http://zh.clicrbs.com.br/rs/noticia/2014/o7/ governo-autoriza-instalacao-de-fabrica-chinesa-em-lages-4563717.html Acesso em: 19 de dezembro de 2015 .

Kaplinsky, R. (2000). "Spreading the gains from globalisation: what can be learned from value chain analysis?” IDS Working Paper 110, Brighton: Institute of Development Studies.

Lins, H. N. (1997). “Competitividade em PMEs de autopeças: estudos de caso no sul do Brasil.” In Solleiro, J. L. \& Faloh, R. (eds.). Memorias del VII Seminario Latinoamericano de Gestión Tecnológica, Tomo III. La Habana: Asociación Latinoamericana de Gestión Tecnológica, pp. 2437-2459.

Loetz, C. \& Benetti, E. (2014). “Montadora alemã abre as portas em Araquari”. Diário Catarinense 10 out. 2014: 6-7.

Marinelli, L. (1998). "Montadoras unem divisões.” Gazeta Mercantil Latino-americana 20 jul. 1998:27.

Nunes, C. (2014). "BMW eleva nível de exigência de fornecedores no Norte de SC.” A Notícia 9 out.. URL [On line]: http://anoticia.clicrbs.com.br/sc/economia/ noticia/2014/10/bmw-eleva-nivel-de-exigencia-de-fornecedores-no-norte-de-sc-4617266.html Acesso em: 19 de dezembro de 2015. 
Santos, A. M. M. M. \& Costa, C. S. (1996). “Autopeças: um setor em transformação.” BNDES Setorial 3:96-107.

Santos, A. M. M. M. \& Pinhão, C. M. A. (2000). "Investimentos do complexo automotivo: atuação do BNDES.” BNDES Setorial 12:3-15.

SINDIPEÇAS/ABIPEÇAS (2006). Desempenho do setor de autopeças - 2006. São Paulo.

SINDIPEÇAS/ABIPEÇAS.(2015). Desempenho do setor de autopeças - 2015. São Paulo.

Sturgeon, T. J. \& Biesebroeck, J. Van \& Gereffi, G. (2008). "Value chains, networks, and clusters: reframing the global automotive industry." ITEC Working Paper Series 08-2, Kyoto: Doshisha University.

Voos, C. H. \& Silva, L. E. de C. (2014). "A BMW em Araquari/SC e o planejamento de ocasião: o Estado como agenciador da flexibilização urbana.” Revista Brasileira de Estudos Urbanos e Regionais 16(2):45-62. 
